\title{
Serine/Threonine-Protein Kinase SMG1
}

National Cancer Institute

\section{Source}

National Cancer Institute. Serine/Threonine-Protein Kinase SMG1. NCI Thesaurus. Code C116680.

Serine/threonine-protein kinase SMG1 (3661 aa, $\sim 411 \mathrm{kDa}$ ) is encoded by the human SMG1 gene. This protein is involved in the phosphorylation of proteins that are involved in nonsense-mediated decay of mRNA. 